\title{
Effect of Immersion Time on the Copper Corrosion in Neutral NaCl Solution
}

\author{
H.X. Liu, B.Y. Hu, Y. Chen", Y.W. Liu, Y. Xie, L. Zhang, Z.N. Yang ${ }^{*}$ \\ Department of Chemical Engineering and Safety, Binzhou University, Binzhou, Shandong 256600, \\ China \\ *E-mail: chen123yu123@163.com (Y. Chen); yangzhongnian@126.com (Z.N. Yang)
}

doi: $10.20964 / 2018.07 .30$

Received: 31 March 2018 / Accepted: 27 April 2018 / Published: 5 June 2018

This paper deals with the investigation of the effect of immersion time on copper corrosion in neutral $\mathrm{NaCl}$ solution in presence of benzotriazole using electrochemical impedance spectroscopy (EIS) and electrochemical noise analysis (ENA). EIS results indicated that the corrosion process of copper in neutral $\mathrm{NaCl}$ solution in presence of benzotriazole can be classified into five steps in our experimental condition. New parameter of corrosion active energy $C_{A E}$ is proposed from $\mathrm{EN}$ analysis to further study the effect of immersion time on copper corrosion in neutral $\mathrm{NaCl}$ solution in presence of benzotriazole, which almost shows the opposite variation trend with charge transfer resistance with immersion time.

Keywords: inhibition; benzotriazole; electrochemical noise; long-term effect

\section{$\underline{\text { FULL TEXT }}$}

(C) 2018 The Authors. Published by ESG (www.electrochemsci.org). This article is an open access article distributed under the terms and conditions of the Creative Commons Attribution license (http://creativecommons.org/licenses/by/4.0/). 